\title{
An Analysis of the Public Protector's Investigatory and Decision-Making Procedural Powers
}

\author{
C Theophilopoulos* and C De Matos Ala ${ }^{\star *}$
}

\section{P.E.R}

Pioneer in peer-reviewed, open access online law publications

Authors

Constantine Theophilopoulos

Charles De Matos Ala

Affiliation

University of the Witwatersrand South Africa

Email

Constantine.theophilopoulos@wits. ac.za

Dematosala@wits.ac.za

Date Submission

29 January 2018

Date Revised

21 April 2019

Date Accepted

21 April 2019

Date published

6 June 2019

Editor Prof C Rautenbach

How to cite this article

Theophilopoulos C and De Matos Ala C "An Analysis of the Public Protector's Investigatory and Decision-Making Procedural Powers" PER / PELJ 2019(22) DOI http://dx.doi.org/10.17159/17273781/2019/v22i0a4351

Copyright

DOI

http://dx.doi.org/10.17159/1727-

3781/2019/v22i0a4351

\begin{abstract}
This article critically analyses the Draft Rules to the Public Protector Act 23 of 1994 and examines the efficacy of the Public Protector's decision-making procedural powers. Several procedural lacunae are identified. In particular the article evaluates the procedural distinction between an investigation and a hearing as defined in the Draft Rules and the Act. It is unclear from a reading of the Draft Rules whether a hearing is simply part of the Public Protector's investigatory process or whether it functions as a separate quasi-judicial decision-making process in its own right. A significant lacuna is the failure to specify the procedural protections available to an implicated person or a witness in an investigation or a hearing. A primary problem with the Draft Rules is the very broad procedural powers awarded to the Public Protector, which are open to procedural abuse. The article suggests a number of amendments to the Draft Rules, which should be modelled on the procedural methodology applied in the Special Investigating Units and Special Tribunals Act 74 of 1996. Moreover, the article suggests that the decision-making powers of the Public Protector should be divided between the Public Protector and an independent and temporarily appointed adjudicator.
\end{abstract}

\section{Keywords}

Public Protector; Draft Rules; investigatory powers; decision-making procedural powers; hearing proceedings; witness procedural protections; special tribunal 


\section{Introduction}

The Public Protector's office (hereinafter the PP) has been the subject of much scholarly reflection. However, this article differs from the existing discourse by taking a unique perspective on the PP. Rather than contemplating the PP's substantive powers, this article focusses on a critical analysis of the procedural aspects of the PP's functions. It seeks to review the PP's procedural methodology, especially in the conduct of its investigations. As with any institution created in terms of chapter 9 of the Constitution of the Republic of South Africa (hereinafter the Constitution), the purpose of the Public Protector's office is to strengthen the constitutional democracy of the Republic ${ }^{1}$ by uprooting prejudice, impropriety and the abuse of power in State affairs. ${ }^{2}$ In order to achieve its constitutional mandate the PP must be an independent, impartial institution which fairly exercises its powers without fear, favour or prejudice. ${ }^{3}$ It is submitted that the PP can exercise its functions legitimately and effectively only if it possesses a comprehensive, clear, and logically ordered set of procedures instead of the present set of ambiguously defined procedures, which permit the PP an unfettered procedural discretion. The procedures governing the investigation and decision-making powers of the PP are briefly alluded to in the Public Protector Act 23 of 1994 (hereinafter the PP Act) and substantially set out in the Draft Rules published in 2010. ${ }^{4}$ The Draft Rules have not been enacted and this failure is a serious omission which has hampered the procedural effectiveness of the decision-making process of the PP's office. There is also very little Superior Court precedent on the procedural powers of the PP and consequently no substantial case law framework on which to pin a critical analysis of these procedures.

According to chapter 1, rule 1, the purpose of the Draft Rules is six-fold, namely, to determine:

Constantine Theophilopoulos. BSC LLB LLM LLD (WITS). Associate Professor, School of Law, University of the Witwatersrand, South Africa. E-mail: Constantine.theophilopoulos@wits.ac.za.

** Charles De Matos Ala. BA LLB LLM H Dip Company Law (WITS). Lecturer, School of Law, University of the Witwatersrand, South Africa. E-mail Charles.Dematosala@wits.ac.za.

1 Sections 181-182 of the Constitution of the Republic of South Africa, 1996 (the Constitution).

2 Economic Freedom Fighters v Speaker, National Assembly 20163 SA 580 (CC) para 56 (hereinafter the Economic Freedom Fighters case).

3 The Economic Freedom Fighters case para 49.

4 Gen N 1085 in GG 33807 of 29 November 2010 (Draft Rules Relating to Investigations by the Public Protector and Incidental Matters). 
a) the procedures for lodging complaints with the PP's office;

b) the procedures for resolving disputes by the PP;

c) the service standards applicable to the PP in conducting investigations and resolving disputes;

d) the timelines for the taking of actions;

e) the timeframes for State organs to respond to a report or finding of the PP; and

f) the steps the PP may take if a State organ fails to adhere to the stipulated timelines.

Unfortunately, the draft rules are badly formatted and poorly written. Many of the rules are grammatically vague and sometimes legally incomprehensible. Rule 1 is a typical illustration of such ambiguity. For example, the term "service standards" in rule 1(1) is not properly explained or alluded to in any of the subsequent rules or the PP Act, so that it is difficult to understand exactly what is implied by this term, and no explanation is offered as to the difference between a "timeline" in rule 1(d) and a "timeframe" in rule $1(\mathrm{e})$. Similarly, in addition to being poorly worded, chapter 2 is deficient in its function as "the definition section" of the Draft Rules, because it omits a number of foundational procedural definitions.

The principal purpose of this article is to critically evaluate the PP's procedural powers by examining the two most important mechanisms (i.e. the investigation and the hearing) at the disposal of the PP in undertaking its statutorily defined functions of resolving disputes and investigating failures of governance in the public sector. Presently, the decision-making ability of the PP is entirely dependent on the investigatory process contained in section 7 of the PP Act as entrenched in section 182(1) of the Constitution. ${ }^{5}$ However, sections 7 and $7 \mathrm{~A}$ of the PP Act set out only a limited number of investigatory procedures with only a limited number of procedural safeguards for implicated persons or procedural checks and balances on the way the PP controls and conducts its investigation. A much more detailed set of investigatory procedures is contained in chapters 5 and 7 of the Draft Rules. Regrettably, the PP is not obliged to follow these procedures, as the Draft Rules have not been promulgated. The failure to enact a complete and legislatively obligatory set of investigatory procedures 
exposes the PP to charges of arbitrary decision-making, lack of objectivity or procedural unfairness. ${ }^{6}$

This article proposes that the PP's principal decision-making mechanism for serious complaints - especially those in the public interest - should be primarily based on an open hearing or alternatively a Special Tribunal modelled on the procedural formula set out in sections 7-10 of the Special Investigating Units and Special Tribunals Act (hereinafter the SIU Act). ${ }^{7} \mathrm{~A}$ tentative type of hearing is set out in chapter 6 of the Draft Rules and a primary lacuna in the Draft Rules is the failure to clearly determine the procedural status of a hearing - when it is resorted to by the PP. It is unclear from a reading of the Draft Rules whether a hearing is simply part of the PP's investigatory process or whether it functions as a separate quasijudicial decision-making process in its own right. As no reference is made to a public hearing mechanism in either section 182 of the Constitution or the PP Act, it is a matter of urgency that the Draft Rules be critically assessed, amended where necessary, and promulgated as soon as possible in order to promote the procedural effectiveness and protect the procedural legitimacy of the office of the PP.

\section{Locus standi of any person}

Chapter 3 , rule 3 , sets out the locus standi of a complainant in very broad and vague terms. Rule 3 does not directly refer to the concept of locus standi but simply states that any individual, person acting on behalf of another person or minor, group of persons or organisation may lodge a complaint in any matter over which the Public Protector has jurisdiction, including a list of ten specific pieces of legislation contained in rule 3(3)(a)-(j). The strength of rule 3 lies in its wide definition of standing and its conformity with the constitutional principle of access to justice, but its weakness is in its failure to properly define what is meant by "any organisation" or "group of persons". For example, may a group of persons be interpreted as including a specific class of persons or a class of juristic persons? In this respect rule 3 should

$6 \quad$ South African Reserve Bank v Public Protector 20176 SA 198 (GP) para 58 (hereinafter the $S A R B$ case). Note that no decision to date has critically commented on the PP's vague set of procedural rules. The High Court here is referring to procedural unfairness with regard to the failure to adhere to the PP's established practice of providing a provisional report.

$7 \quad$ Special Investigating Units and Special Tribunals Act 74 of 1996. 
be redrafted along the lines of the very clear, precise and wide definition of locus standi contained in section 36 of the Constitution. ${ }^{8}$

Similarly, rule 4 peremptorily requires certain personal and factual information from a natural complainant when reporting a complaint and certain additional information from a complainant defined as "not a natural person". The term "not a natural person" sometimes confusingly refers to an organisation in subrule 4(2), a company in subrule 4(4)(a) and a juristic person in subrule 4(4)(b). To add to the confusion, reference is made in rule $5(2)(f)$ and (i) to any "institution" or "entity" without explaining the juristic meaning of these words. This is in contrast to section 5(1) of the PP Act where the office of the PP is consistently referred to as a juristic person.

Rule 6 discretionarily allows a complainant to request that any personal information disclosed by way of an oral or written declaration under oath be kept confidential, but the PP may decline to investigate a complaint where the complainant refuses to consent to disclosure when requested to do so. ${ }^{9}$ Rule 6(3) offers only a limited protection to the whistle-blower as it does not provide a reasonable form of immunity from prosecution. In this respect rule 6 may well discourage the reporting of complaints and restrict access to justice, thereby undermining the wide definition of standing set out in rule 3 .

\section{Types of complaints and jurisdiction}

In contrast to a number of other poorly drafted rules, rule 5 read with section 6(4) and (5) of the PP Act, which contains the jurisdictional investigatory powers of the PP, is plainly and precisely set out with some minor exceptions. The PP may investigate any conduct (actual or alleged) in State affairs or public administration in any sphere of government. ${ }^{10}$ However, the PP is specifically excluded from investigating the performance of judicial functions by any court of law. ${ }^{11}$ Rule 5(2)(a)-(o) allows the PP to investigate

$8 \quad$ Democratic Alliance $v$ South African Broadcasting Corporation Limited 20151 SA 551 (WCC) paras 24, 28-32, an applicant "has standing to act in its own interests, those of its members as well as in the public interest" and this standing may be grounded on (i) respect for the rule of law, (ii) the principle of legality, (iii) strengthening of democracy and (iv) public accountability and governance. See Public Protector v Mail \& Guardian 20114 SA 420 (SCA) paras 28-29 (hereinafter the Mail \& Guardian case) which explained standing in terms of its common law definition. Also see Democratic Alliance $v$ President of the Republic of South Africa 20131 SA 248 (CC). Also see Venter 2017 TSAR 176, 178-181.

$9 \quad$ Section 6(1)(a) of the PP Act read with r 7(1)(2) and (3) of the Draft Rules.

10 Section 6(7): the PP shall investigate on its own initiative any alleged attempted act or omission as defined in subsecs (4) and (5) read with $r$ 5(2). See the Economic Freedom Fighters case para 53; Mail \& Guardian case para 10.

11 Section 6(6) of the PP Act. 
any positive acts or omissions in the affairs of government at any level (including the exercise of a pubic function by any person) in the form of any maladministration, abuse or unjustifiable exercise of power, ${ }^{12}$ dishonesty, impropriety, unlawful enrichment or improper advantage (including the promise of such advantage), prejudice to any person, unfair discrimination, hate speech or harassment. ${ }^{13}$

The PP may also investigate conduct as defined in a number of specified statutes (some but not all of which are also included in rule 3(3)), ${ }^{14}$ such as offences defined in the Prevention and Combating of Corrupt Activities Act, ${ }^{15}$ maladministration in respect to the Public Finance Management Act, ${ }^{16}$ breach of ethics in terms of the Executive Members' Ethics Act, ${ }^{17}$ a decision of the Housing Protection Measures Act, ${ }^{18}$ contraventions of the Promotion of Equality and Prevention of Unfair Discrimination Act, ${ }^{19}$ and infringements of the Promotion of Access to Information Act. ${ }^{20}$

The PP's competency also applies to attempts to perform any act which the PP may ordinarily investigate or resolve. ${ }^{21}$ In essence the PP has a wide discretion in framing the issues in dispute.

In terms of geographical jurisdiction a complaint must be lodged with the office of the PP in the area where the incident or conduct complained of occurred but the PP may transfer a complaint to any other office. ${ }^{22}$ Geographical jurisdiction is based on the common law principle of actio rei gestae but rule 9(a) omits the complementary principles of actor sequitur

12 Rules 5(2)(b) and (c) refer to unfair, capricious, discourteous or improper conduct. While the words "unfair" and "improper" are capable of legal interpretation as a standard of conduct, the words "capricious" and "discourteous" are vague terms of art which are not capable of legal definition. Rule $5(2)(n)$ in respect to complaints referred to the PP by the Equality Court. Rule 5(2) may be arbitrary in the sense that it specifically omits a number of important Acts set out in r 3(3), namely, the Protected Disclosure Act 26 of 2000, Lotteries Act 57 of 1997 and the National Environmental Management Act 107 of 1998. Prevention and Combating of Corrupt Activities Act 12 of 2004.

Public Finance Management Act 1 of 1999.

Executive Members' Ethics Act 82 of 1998.

Housing Protection Measures Act 95 of 1998.

Promotion of Equality and Prevention of Unfair Discrimination Act 4 of 2000. Although why the word "contravention" is qualified by the word "persistent" is unclear.

Promotion of Access to Information Act 1 of 2000. When s 110 of the Protection of Personal Information Act 4 of 2013, which repeals s 6(4)(d) of the PP Act comes into operation, the PP will no longer have the power to resolve disputes concerning the operation of the Promotion of Access to Information Act.

21 Section 6(7) of the PP Act read with $\mathrm{r}$ 5(2)(j).

22 Rule $9(2)$ is ambiguous and arbitrarily allows the PP to transfer a complaint to another regional or provincial office without giving any reasons for the transfer. 
forum rei, convenience and submission/consent, which would have significantly widened the PP's geographical jurisdiction and enhanced a complainant's access to the PP's office.

\section{Lodging and reporting procedures}

In general a complaint should be lodged by way of a written affidavit or oral declaration under oath or affirmation. ${ }^{23}$ All complaints must be made in writing and a formal complaints form is available at all PP provincial and regional offices. ${ }^{24}$ Oral complaints are exceptionally permitted but only where it is impossible for a person to reduce a complaint to writing or where the complaint concerns an urgent matter. ${ }^{25}$ Rule $7(6)$ is unique in the sense that it allows a complainant with disabilities or a language barrier or for any other reason to lodge a complaint by way of a signed letter, e-mail or complaint form. ${ }^{26}$ This is done in order to make the PP's office accessible to all persons. ${ }^{27} \mathrm{~A}$ complaint may be addressed to the PP and physically handed in or faxed to any office of the PP with jurisdiction to hear the matter. Alternatively it may be sent by registered post or lodged electronically by accessing the on-line complaints form. ${ }^{28}$

A complaint prescribes after two years from the occurrence of the incident or matter complained of but the PP may waive prescription on good cause shown. ${ }^{29}$

23 Section 6(1)(a): the written or oral declaration should contain the nature of the complaint, the grounds for a possible investigation and any other relevant information. Section 6(1)(b): a complaint may also be lodged by any other means which the PP may allow to make the office more accessible.

$24 \quad$ Rule 7 read with s 6(1) of PP Act.

25 Rule $7(3)$ is ambiguous as it is unclear what circumstances would constitute an impossibility or urgency permitting oral reporting. Note, an oral complaint must be reduced to writing, verified, amended and recorded by the PP (r 3(4)(a)-(d)). Rule 7(5) is ambiguous as it refers to a disability or language barrier or other reason - it is uncertain what constitutes an "other reason". Section 6(1)(b) of the PP Act read with s 182(4) of the Constitution. See the Economic Freedom Fighters case para 65: "...and also to ensure that the efficient and effective use of resources is promoted". Rule 8(2). Also see s 6(2) of the PP Act, where a member of the PP's office must assist any person to lodge a complaint. whether a refusal to investigate will result in prejudice to any person, (iii) any other practical remedy or solution is available, and (iv) the prospects of success in resolving the complaint. The rule is also silent on whether prescription may be interrupted or suspended. 


\section{Procedure after the reporting or lodging of a complaint}

Chapter 4, rule 11, allows for a two-step process. First, the Public Protector must after receiving a complaint open a file, allocate a reference number to the complaint, and within 5 court days from the date of receipt acknowledge the receipt thereof. Within the same 5 court days the PP must determine whether the complaint is jurisdictionally sound, assign an investigator and within a further 5 court days inform the complainant of the investigator's contact details. ${ }^{30}$

Secondly, a preliminary investigation is usually undertaken where the merits of the complaint or the appropriate manner of dealing with the complaint are uncertain. ${ }^{31}$ All preliminary investigations whether in terms of rule 11(7) or rule 15(1) must be completed within 10 court days unless specific circumstances justify a longer but reasonable delay. ${ }^{32}$ Where a complaint is lodged outside the prescribed time period, ${ }^{33}$ the PP must in terms of rule 12 acknowledge receipt thereof within 3 court days, decide on whether or not to take on the complaint within 5 court days of receipt, ${ }^{34}$ and within a further 5 court days after reaching a decision inform the complainant thereof. ${ }^{35}$

The problem with rules 11 and 12 is that they set out unrealistic and narrow timelines of between 3 to 5 court days whereas rule 15 sets out a timeline of 10 court days for a preliminary investigation but allows for a flexibly longer period where reasonably justified. Experience has demonstrated that the shortage of skilled personnel and cost restraints within the PP's office may make these short timelines unreasonable and unmanageable. ${ }^{36}$

On the other hand section $7(11)$ of the PP Act grants the PP an unreasonably wide-ranging power to make rules with regard to any matter in section 7 which has a bearing on any investigation, subject to publication in the Government Gazette and tabling in the National Assembly, ${ }^{37}$ while

\footnotetext{
$30 \quad$ Rule 11(1)-(6).

$31 \quad$ Rule 11 (7)-(8) read with s 7(1)(a) of the PP Act.

32 Rule 15(2)-(3) the complainant must be informed of the longer period in any manner deemed fit by the PP. The term "outside the prescribed time period" presumably refers to the 2 year prescription period. information, (b) the degree of delay, (c) that the outcome of the investigation would correct a systematic State problem, (d) the likelihood of a successful investigation and (e) any other relevant factor.

$35 \quad$ Rule 12 (1)-(2) read with $r$ 14(2).

$36 \quad$ See the $S A R B$ case para 59.

37 Section $7(11)$ of the PP Act.
} 
rule 54 permits the PP to condone a failure to comply with the rules on good cause shown. Rule 54 is ambiguous as it makes no mention of the prejudice which may occur to another party when a failure to comply with a rule is condoned by the PP. The rule confusingly states that the PP may condone "on the conditions he/she may deem fit" - what constitutes a "condition" is not explained. The rule also confusingly states "or take measures to exact accountability" - what the word "accountability" amounts to is also not explained.

\section{Joining parties and consolidating complaints}

In terms of chapter 9, rule 35(1), the PP may of its own accord or on application by a party or other person join or substitute any number of persons or institutions as parties to the proceedings where their right to corrective action depends on substantially the same question of law or fact or the parties have a substantial interest in the subject matter of the proceedings. ${ }^{38}$ Rule 35(1) fails to distinguish between joinder of convenience and joinder of necessity. Presumably the use of the test "same question of law or fact" in rule 35(1)(a) implies joinder of necessity and the test "a substantial interest in the subject matter" in rule 35(1)(b) implies a joinder of necessity. The rule also fails to explain what is meant by the word "substitution". No mention is made of waiver of joinder or the procedural consequences of misjoinder or non-joinder. The rule is silent about intervention by another party or about submissions by amicus curiae.

Rule 36 allows the PP on its own initiative or on application by a party to consolidate two or more complaints and deal with the consolidated complaints in the same proceedings. The word "consolidation" probably refers to a joinder of complaints. The rule is silent on whether or not the PP may consolidate complaints which conflict with each other. The rule is also silent on whether consolidated complaints may be separated and dealt with in separate proceedings.

It is also assumed that the word "proceedings" used in the rule caption under chapter 9 refers not only to complaints resolved by alternative dispute resolution processes (hereinafter ADR) but to all proceedings initiated by a complaint, including the investigation and the hearing.

38 Rule 35(2): joinder or substitution is made by way of an application, which presumably means a founding affidavit containing the reasons for the proposed joinder or substitution, and any attached relevant documentation. 


\section{Procedural pathways in resolving a complaint}

The procedural pathways in resolving complaints are not clearly set out in either the Draft Rules or the PP Act. It is argued that in order to make the PP more accessible to all persons, rule 7 should be interpreted as setting out a number of procedural pathways based on the distinction between minor and serious matters. ${ }^{39}$

The first procedural pathway concerning minor matters allows complaints that are not made under oath or affirmation. The first procedural pathway as determined by rule 7(1) read with section 6(4)(b) of the PP Act allows the PP to proceed discretionally by way of conciliation (rule 40), negotiation (rule 41) or mediation (rule 42). In addition the PP may refer a complaint to a relevant public authority, recommend litigation or make any other recommendation which may be appropriate, taking into account the nature of the issues under investigation and any possible anticipated finding, on the sound logic that "every complaint requires a practical or effective remedy that is in sync with its own peculiarities and merits". ${ }^{40}$

The second procedural pathway concerning all serious complaints may proceed by way of ADR but is more likely to proceed by way of an investigation or an inquisitorial hearing as defined in chapter 6 , rules 18 to 27.

Rule 33 clearly states that the PP must resolve a complaint at the earliest opportunity and must within 5 court days after having considered the most appropriate method of resolving the complaint inform the parties in writing of the selected method, with reasons. However, where the parties disagree with the selected method rule 35(3) and (4) provides the parties with an opportunity to make representations, together with reasons for their disagreement. Unfortunately, the rule is silent about whether the PP has the discretion to dismiss such reasons even where they are cogent. being discharged, may be resolved without investigation, is not an offence, does not concern dishonesty, and does not concern defamatory information. 


\section{Investigating a complaint or matter}

The PP's powers of investigation are proactive, ${ }^{41}$ extensive, ${ }^{42}$ wide-ranging, potentially intrusive, and do not "bow down to anybody, not even at the door of the highest chambers of raw State power". ${ }^{43}$ An investigation is a procedurally flexible, informal and factual proceeding instituted by the PP on its own initiative with due regard to the circumstances of a particular case. ${ }^{44}$ The format of an investigation in terms of chapter 5 , rule 13(1) may consist of any combination of a simple communication by telephone, e-mail or other correspondence, a meeting with affected parties believed to have relevant information, an appearance before the PP for questioning or the production of documents, a hearing to obtain evidence, ${ }^{45}$ a meeting to examine and copy documents in the possession or the control of a State organ, and most importantly a public hearing to obtain public comment on a matter of broad public concern. In addition, in terms of rule 13(2) the PP may obtain relevant information for an investigation by way of a statement from a State organ, ${ }^{46}$ or by attending any administrative hearing or any other relevant proceedings. ${ }^{47}$

In order to conduct an effective investigation the PP is empowered by a number of procedural devices to oblige co-operation by State organs and any other necessary persons. Rule 16(1) read with section 181(3) of the Constitution legally obliges all State organs to protect the independence, impartiality, dignity and effectiveness of the PP and to co-operate with the $P P$ by providing access to their premises and to all data in their possession. Section 7(3)(a) of the PP Act allows the PP to request any person at any level of government or performing a public function or otherwise subject to the PP's jurisdiction to assist in an investigation under the supervision of the PP. ${ }^{48}$ Similarly, s 7(3)(b)(i) of the PP Act empowers the PP to deputise a

41 The Mail \& Guardian case paras 9-11.

42 South African Broadcasting Corporation v Democratic Alliance 20162 SA 522 (SCA) para 38.

43 The Economic Freedom Fighters case paras 55, 67.

44 Section 7(1)(b) of the PP Act read with $\mathrm{r}$ 14(1).

45 Rule $13(1)(d)$. It is unclear what the legal distinction is between the words "an appearance" and a "meeting" before the PP.

46 Rule 13(2)(a)-(b): statements from State organs providing reasons for taking an administrative action or providing any relevant information for the investigation.

$47 \quad$ Rule 13(2)(c).

48 Section 7(3)(a) of the PP Act is ambiguous as it is unclear whether the requested assistance is obligatory or discretionary. Also see $s 3(12)$, which allows the secondment of public/state officers to the service of the PP. 
person to conduct an investigation in whole or in part with such powers as may be delegated by the PP. 49

Rule 16(2) directs any person to submit an affidavit or declaration of relevant evidence or to physically appear before the PP to give evidence relevant to an investigation. Such co-operation may be enforced by means of a subpoena. ${ }^{50}$ Apart from a subpoena, rule $17(1)(b)$ read with $s 7 A$ of the $P P$ Act permits the PP to obtain a warrant of search and seizure from a designated magistrate or judge, ${ }^{51}$ and to enter, search and seize anything on the identified premises relevant to an investigation. ${ }^{52}$

Unfortunately, the attempt to reconcile the principle of co-operative governance with the PP's information gathering powers creates an unjustified limitation on those powers. Rule 17(1) provides that the PP must first "endeavour to seek the co-operation" of the relevant State organ before the PP may issue a subpoena or obtain a warrant. ${ }^{53}$ Firstly, this limitation is too general in its application. An "endeavour" to obtain co-operation may merely warn those guilty of malfeasance of an impending investigation and give them time to destroy or fabricate evidence. Secondly, the rule is vague as to the manner and time periods within which co-operation must be sought.

In practice the PP's investigation amounts to a continuous or overall process comprising a number of distinct "interviews". To secure cooperation a witness may be subpoenaed by the PP to give evidence. The method or nature of an interview depends on the status or nature of the witness (i.e.

Sections 3(13)-(15) of the PP Act: a person designated to conduct an investigation must perform in good faith, without fear, favour, bias or prejudice and may not have a pecuniary interest in the investigation. The failure to declare an interest permits the PP to take such steps as are necessary to ensure a fair, unbiased investigation. See the offences and penalties set out in $\mathrm{s} 11$ of the Act. Section 7(3)(b)(ii) provides that a person designated to conduct an investigation is remunerated on the same basis as a person conducting a commission of inquiry.

50 Rule 16(2) read with $r$ 17(1)(a) and $s$ 7(4) and (5). A subpoena must be signed by the PP and served either by registered letter or personally by an authorised person. Also see $r 50(a)$. The rules are silent on the penalty (i.e. arrest) for failing to obey a summons.

51 Note: the PP has the power to issue a subpoena, but a warrant must be issued by a judicial officer on the PP's instruction.

52 Sections 7A (1)-(8) of the PP Act: the same rules apply as with any other criminal warrant of search and seizure. A warrant expires after 3 months unless executed or cancelled. Note: subsec (8) allows a person to claim attorney-client privilege over work documents which are excluded from seizure. Also see $r 50(b)$.

53 See $\mathrm{r} 49$, which provides that the PP may make use of "the powers provided for in the Act" where a State organ fails to co-operate voluntarily. Essentially the Draft Rules envisage an attempt by the PP to obtain voluntary co-operation before the PP resorts to its ss 7 or $7 \mathrm{~A}$ powers. 
friendly or suspect, cooperative or hostile). Where an "implicated person" is involved, the interview is potentially more of an interrogation. Hence the right to be assisted by a legal representative. ${ }^{54}$ However, the PP Act and Draft Rules are silent on an implicated person's right to silence or an ordinary witness's privilege against self-incrimination.

Interestingly, while the Draft Rules allows for information to be gathered by means of telephonic communication or correspondence, ${ }^{55}$ the PP Act empowers the PP only to "direct" a person to submit an affidavit or to appear before the PP to give evidence. ${ }^{56}$ Such a direction is effectively a subpoena, which must be issued by the PP and duly served on the intended witness. ${ }^{57}$ Moreover, an oath or affirmation may be administered only to a person appearing before the PP as a witness. ${ }^{58}$ The Draft Rules and the PP Act are silent as to whether a telephonic or video conference would qualify as an appearance before the PP. Absent such clarity, no person can be compelled to give evidence during informal meetings or telephone discussions.

Where during the course of an investigation it appears that a particular person is being implicated or that an adverse finding may be made, the person shall be afforded an opportunity to respond to the implication or adverse finding. ${ }^{59}$ Similarly, where the implication forms part of the evidence submitted to the PP during an appearance, the implicated person shall be afforded the opportunity to respond by adducing contrary evidence and the opportunity to question any other witness appearing before the investigation. 60

A failure to co-operate with the PP may result in the imposition of a sanction, offence or any other adequate procedure provided for in the PP Act including the initiation of disciplinary proceedings against recalcitrant public officials. ${ }^{61}$ The latter would prove a useful deterrent and a rule to that effect ought to be enacted. Interestingly, while the PP Act criminalises Section 7(8) of the PP Act. Note: a witness may refresh his/her memory from any relevant document or record.

55 Rule 13(1).

56 Section 7(4)(a) of the PP Act.

57 Section 7(5) of the PP Act.

58 Section $7(6)$ of the PP Act.

59 Section 7(9)(a) of the PP Act.

60 Sections 7(9)(b)(i)-(ii) read with s 7(4) of the PP Act.

61 Rules 17(2) and (3) and s 11 of the PP Act.
} 
"interference with the functioning" of the PP, it does not clarify whether noncooperation amounts to interference. ${ }^{62}$

Another potential remedy available to the PP to obtain cooperation is section 9 of the PP Act, which deems certain conduct committed in relation to the PP to be contempt of court. 63 "Contempt of Public Protector" arises if a person's conduct would have constituted contempt of court if the PP's investigation "had been proceedings in a court of law". Arguably, if the PP commanded a person to cooperate in the course of an investigation, any failure to do so would amount to contempt. Unfortunately, no reference to contempt is made in the rules governing an investigation or a hearing.

\section{Referrals and joint investigations}

Chapter 7, rules 28-30, covers three referral processes, namely:

a) the referral of complaints by the PP to other public bodies or authorities;

b) referrals of complaints to the PP by other public bodies or authorities; and

c) the PP's advice to the complainant concern the appropriate forum.

The PP has the discretion to refer a complaint to an appropriate public body if the PP deems it advisable or expedient for that body or authority to deal with the complaint. In doing so the PP may also make "appropriate recommendations" to the body or authority regarding the redress of the prejudice arising from the behaviour complained of. ${ }^{64}$ The Draft Rules are silent on the meaning of "recommendation", which may be presumed to mean "a suggestion or proposal as to the best course of action". 65 In essence a recommendation is not peremptory, ${ }^{66}$ and it may be argued that

62 Section 11(1) of the PP Act read with s 181(4) of the Constitution. The Economic Freedom Fighters case para 53 held that the President's failure to give effect to the PP's remedial action was a breach of the President's duty to assist and protect the PP under s 181(3) of the Constitution. A contravention of $\mathrm{s} 9$ of the PP Act is a criminal offence punishable by a fine not exceeding R 40000 or 12 months imprisonment, or both a fine and imprisonment (ss 11(1), (4)).

64 Section 6(4)(c)(ii) of the PP Act.

65 Oxford Dictionary of English 1484

66 The SARB case para 55. 
unlike the PP's remedial actions, the PP's recommendations are not binding on the body or authority receiving the referral. ${ }^{67}$

The PP's power to make a referral arises at any time before, during or after the conduct of an investigation. ${ }^{68}$ The decision to refer a complaint is often a rational one, given the fact that the PP "is expected to deal with at times complex and challenging matters with limited resources and without the benefit of rigorous forensic techniques". 69

Rule 28(1) expands and elaborates upon the PP's power of referral, providing that in addition to the circumstances described in section 6(4)(c) the PP may refer complaints, principally where the complainant has not taken reasonable efforts to resolve the complaint against a State organ, ${ }^{70}$ or is an officer or employee of the State who has not exhausted the remedies afforded by the Public Services Act, ${ }^{71}$ or has failed to exhaust his or her ordinary legal remedies, ${ }^{72}$ or that another public body or authority is already investigating the matter. In each of these instances the purpose is to prevent unnecessary duplication of effort. Thus, in the first two instances, a complaint to the PP would be regarded as premature as the complainant has not exhausted the remedies already afforded to him or her. Interestingly, while section 6(3) merely provides that the PP may refuse to investigate premature complaints, rule 28(1) provides that the PP may refer the complaint to the appropriate body or authority. Arguably, what rule 28(1) envisages is the PP remitting the complaint to the state organ complained of in order for it to make a final decision in terms of its internal grievance procedures.

Rule 28(3) requires the PP to allow the parties "a reasonable opportunity to respond to the intended referral". Presumably the notice furnished to the parties will detail whether the PP will entertain oral or written argument as to the decision to refer a complaint. Other than obliging the PP to consider the parties' representations concerning a referral, the rules do not limit the PP's discretion to refer a matter. This is how it should be, as the referral rule enables the PP to free up its capacity to deal with more pressing matters. Similarly, it enables the PP to ensure that a complainant receives the best treatment from a better resourced or more appropriately skilled institution.

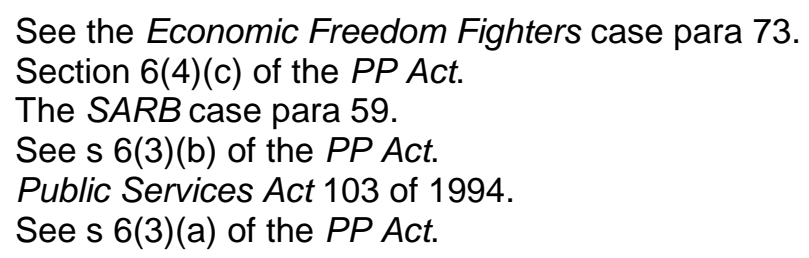


Rule 29(a) states that the PP must accept a complaint referred by another public body or authority if it falls within the PP's jurisdiction. Once the complaint is accepted the PP must inform the parties in writing of the referral. On conclusion of the complaint, the PP may report on the outcome of the matter to the body or authority that referred it. ${ }^{73}$

Section 6(4)(b)(ii) provides that one of the ways in which the PP may resolve a dispute or rectify an act is by advising a complainant on the appropriate remedies. Rule 30(1) elaborates on the PP's advisory remedy, stating that the PP may advise the complainant to approach an appropriate institution if the PP has no jurisdiction or if another institution provides the appropriate remedy. However, unless the PP Act empowers the PP to refuse to investigate a matter, the PP is compelled to investigate it if the PP has jurisdiction and the complainant insists the PP investigate it. ${ }^{74}$

For reasons of procedural economy chapter 9 , rule 31 , allows the PP to conduct a joint investigation with another institution or State organ in certain circumstances. First, where the mandates of the PP and the other institution overlap "in respect of the resolution of the complaint" - the rule appears to have the Special Investigating Unit in mind. Second, where the PP lacks the resources, capacity or expertise to resolve a matter without the other institution's assistance. Third, where the nature and complexity of the matter is such that it warrants collaboration between the PP and the other institution. Finally, where a matter is of a type covered by a collaboration agreement between the PP and an institution with a complementary mandate. Before embarking on a joint investigation the PP must inform the parties of the proposed joint investigation, the identity of the other institution, and the reasons for the joint investigation. The parties are entitled to lodge their objections to the proposed joint investigation. ${ }^{75}$

\section{The conduct and procedures of a hearing}

The procedures governing a hearing are not set out in the PP Act and are entirely contained in the Draft Rules. The principal problem with the procedural status of a hearing is that neither the PP Act nor the Draft Rules attempts to explain the procedural relationship between a chapter 5 investigation and a chapter 6 hearing.

Rule 29(c).

Rule 30(2).

Rules 32(1) and r 32(1)(b). 
Chapter 6 of the rules may be interpreted as setting out a four-step process for the conduct of a hearing. These four steps include (i) the circumstances which in the opinion of the PP require the holding of a public hearing (rules 18-19), (ii) the notice requirements for a hearing (rule 20), (iii) the persons allowed to attend a hearing (rules 21-23), and (iv) the nature and procedures utilised in the conduct of a hearing (rules 24-27).

\subsection{Circumstances requiring a hearing}

Rule 18 unambiguously states that the PP on its own discretionary initiative or at the request of an interested party may in certain circumstances constitute a hearing. However, the circumstances which allow for constituting a hearing are broadly and vaguely defined. These circumstances are (a) where a complaint cannot be resolved by any other means referred to in the rules and a hearing will allow for an appropriate resolution of the complaint, and (b) a hearing will allow the PP to reach an appropriate conclusion regarding the complaint. These two circumstances are ambiguously defined and it is difficult to understand the precise difference between them. The additional circumstances include (c) where the PP deems it in the public interest to hold a hearing, and (d) where the complaint cannot be fairly decided only on the basis of documentary evidence or written statements or relevant information. Again, this circumstance is difficult to interpret and presumably means that oral witness evidence will be required to decide the complaint. Circumstance (e) allows a party to request a hearing on reasonable grounds. Exactly what reasonable grounds would allow for a hearing is unclear and omitted from the rules.

In terms of rule 19 a party requesting a hearing must set out the reasons for such a request and the material issues to be raised at a hearing. It is not clear from rules 18 or 19 whether the PP is obliged to hold a hearing when a party supplies cogent reasons or whether the PP may exercise its discretion and refuse a hearing despite the existence of such cogent reasons.

Furthermore there is no provision in the Draft Rules which bars the PP from simply making a decision based purely on the results of an investigation and without holding a hearing. At present this is the PP's established practice.

\subsection{Notice requirements for a hearing}

The notice requirement in rule 20 is clearly set out and requires the PP to give all parties formal notice at least 15 court days before a hearing, unless 
the parties agree to a shorter period. The notice contains the usual administrative detail as to place, time, date, the names of the parties invited/required to attend and a description of the documentary or other evidence to be submitted at the hearing.

A unique feature of the notice is that it allows the PP to decide whether a party may be assisted by legal representation at the hearing and permits a party the opportunity to give reasons why a legal representative is necessary where such a request is initially denied by the PP. ${ }^{76}$ It may be argued that this unique feature of rule 20 constitutes an unreasonable infringement of a person's constitutionally entrenched right to legal representation. Where a party is permitted to employ the services of a legal representative the legal costs of such representation must be borne by the party in terms of rule 53 , as the PP may not make any cost orders.

Finally it is noted that section 10 of the PP Act permits the PP to discretionally award expenses incurred by any person in the course of an investigation, but this type of compensation is not extended to expenses incurred by a person or party to a hearing. At best the language of section 10 suggests that the PP may award out-of-pocket expenses to a witness at a hearing.

\subsection{The attendance requirements of a hearing}

The attendance requirements set out in rules 21 to 23 are both peremptory and discretionary in places. Rule 21 peremptorily requires the attendance of the complainant irrespective of whether or not the complainant is legally represented. Rule 21 , as with rule 20 , is arguably an unreasonable infringement of a party's constitutional right to legal representation. Rule $22(1)$ is discretionary and allows the PP to continue or to postpone a hearing where a party is absent from the hearing but legally represented. The rule fails to mention that there may well be justifiable reasons why a party is absent.

It is unclear whether the word "party" in rule 22(1) refers to a complainant or any party or both. The PP may also continue with a hearing and issue a subpoena to compel an absent party to attend the hearing on a subsequent date. ${ }^{77}$

$\begin{array}{ll}76 & \text { Rules 20(3)(f) and (4)(a)-(b). } \\ 77 & \text { Rules 22(1)(c) and (2). }\end{array}$ 
According to rule 23 read with rule 20 , attendance at a hearing is reserved for a select category of named and invited persons. Therefore, it is unclear whether a hearing is an open public hearing or a closed hearing limited to the following invited persons

a) the complainant;

b) a person required to provide assistance to the PP;

c) a person authorised to conduct a hearing on behalf of the PP;

d) a person required to give evidence or to disclose documentary evidence; and

e) any other person with a vested interest in the matter before the hearing.

The wording of subrule (e) is open to criticism as it is unclear how the term "vested interest" is to be defined. The subrule also allows the PP to exclude any undesirable person from a hearing, as in an investigation. ${ }^{78}$

It is also difficult to determine how the limited attendance requirements of rule 23 may be reconciled with rule 18(c), which allows for a hearing in the public interest. A public interest hearing is by definition open to all interested parties and to all members of the public.

\subsection{The conduct of a hearing}

A PP hearing is defined as an informal recorded procedure which is inquisitorial in nature, although it is clear from a reading of rules 24 through to 27 that a number of minor adversarial procedures may be utilised at the discretion of the PP. ${ }^{79}$ As with the well-established civil practice of the small claims court before a commissioner, the PP must conduct the hearing in an informal but direct manner and according to rule 25(8)(c) in a fair and impartial manner. A hearing, as with an investigation, or any other proceedings of the PP, is conducted in English in terms of rule 52, although a party may make use of the services of an interpreter. A witness appearing before the PP may be required to take the oath or make an affirmation where the PP deems it necessary according to rule 25(10).

See s 7(1)(b)(ii) of the PP Act.

Rule 51: all investigations and other proceedings before the PP shall be recorded and all persons present must be informed of the manner of recording. 
Rule 24(4) gives the PP wide-ranging powers of questioning in the form of an examination-in-chief, and the PP may at any stage of the hearing

a) put any question to a witness;

b) rephrase a question put to a witness by a person or a party;

c) clarify any uncertainties in respect to any given evidence; and

d) elicit information from any witness.

Subrule (4) is vague as it is unclear what the difference is between (a) putting any questions to a witness and (d) eliciting information from a witness. In addition, nothing in subrule (4) bars the asking of leading questions. The rule makes no mention of critical procedural protections such as the privilege against self-incrimination and a constitutionally derived right to silence.

Rule 24(3) read with section 7(9)(b)(ii) of the Act allows a party to put questions to any witness but only through the PP. This qualification is illogical as it is difficult to understand how a party may freely put questions to a witness through the filter of the PP. It also prevents a party from directly using the well-established techniques of cross-examination and restricts a party in its ability to establish the mendacity, demeanour and credibility of an opposing witness.

Rule 26(1) states that the formal rules of evidence do not apply and that the admissibility of evidence is at the discretion of the PP. This means that essential common law rules of evidence such as relevance, hearsay and privilege may be ignored at the discretion of the PP in its search for legal truth.

A hearing commences with an opening statement from the PP in terms of rule 25(1), (2) and (3), in which the PP explains the purpose of the hearing, its inquisitorial nature and the procedures to be followed by the parties and witnesses. The opening statement also contains a summary of the complaint, the issues to be decided and the order in which the evidence will be led.

The inquisitorial procedural powers of the PP are manifested in rule 25(4)(8), which permits the PP 
a) to make a determination about any disclosed document or information - without the need to adhere to the originality/authenticity rules of documentary evidence;

b) to give directions on any other aspect of the hearing - although it is unclear what the legal meaning of the word "directions" is; and

c) to receive evidence from any person at any place and in any manner, including teleconferences, as is deemed fit - clearly without the need to adhere to the hearsay rule.

Rule 25(9) reinforces these inquisitorial powers by awarding the PP the wide-ranging procedural power to take any step necessary to establish the truth and correctness of any statement, submission or given evidence.

The inquisitorial nature of the hearing is ameliorated slightly by rule 25(8)(a)(b), which provides a party with a reasonable opportunity to respond to the evidence adduced at the hearing by (i) giving evidence, calling witnesses, handing in documents and written submissions, (ii) putting questions through the PP to a witness either personally or by way of a legal representative by way of a limited and indirect form of cross-examination presumably to an opposing witness who has given adverse evidence against the party, although this is not clearly stated in rule 25(8), and (iii) making a statement personally or through a legal representative - although it is unclear to whom this statement is directed. Is it addressed to the PP or to a witness?

At the end of the hearing the parties are in terms of rule 25(12) permitted a reasonable opportunity to make closing statements and to have such a statement made either personally or through a legal representative although the grammatical meaning of this subrule is somewhat confusing.

In terms of rule 25(11)(a) the PP is discretionally allowed to accept evidence behind closed doors where it is in the interests of the hearing to do so. Only the interests of the PP are referred to in this subrule and not the protectable private interests of a party or witness, which is also an important evidentiary reason for holding an in camera proceeding. However, both parties are peremptorily allowed an opportunity to address the PP in this regard although it is unclear why the word "both" is used to qualify the word "parties" in rule 25(11)(c). The PP may give any directions as to the disclosure or publication or prohibition of any evidence and information obtained behind closed doors. Unfortunately it is unclear what the words "any directions" mean. 
The principal failing of a chapter 6 hearing is the fact that the two rules determining the decision-making ability of the PP are simply legally incomprehensible. Rule 26(2) allows the PP to decide when sufficient evidence has been given in which a finding can be made and rule 27 holds that the PP must conclude the hearing by evaluating the evidence submitted to a hearing and make a finding on the facts. Both rules are silent as to the universally accepted legal standards upon which the PP must base its decision. First, rule 26(2) makes no reference to a prima facie case - the legally defined meaning of sufficient evidence. Second, rule 27 does not refer to the universally accepted standards of proof in the form of a balance of probability or beyond a reasonable doubt. Therefore, both rules seem to allows the PP to make arbitrary decisions based on an unknown standard and where necessary to take remedial action. However, it was held in President of the Republic of South Africa v Office of the Public Protector that it is unnecessary for the PP to make firm findings on the evidence it gathers. ${ }^{80}$ Rather, the Constitution read with sections $7(1)(a)$ and $8(1)$ of the PP Act envisages that the PP is capable of taking remedial action "on the basis of preliminary or prima facie findings". ${ }^{81}$ Therefore, rule 26(2) should be amended to state that the PP make its findings based on a prima facie standard.

\section{A hearing by special tribunal}

The procedural strengths and weaknesses of the PP's chapter 6 hearing may be illustrated by comparison with section 7 of the SIU Act. A number of critical procedural differences exist between the conduct of a PP's hearing and that of the Special Tribunal, and these are grounded in (i) the composition and membership of the hearing, (ii) public participation in the hearing, and (iii) the consequences of the hearing.

First, the PP's investigation and hearing process is chaired by the PP itself or a designated official of the PP's office, whereas the head of the Special Investigatory Unit is separate from the Special Tribunal, which is chaired by a judge or retired judge of the High Court. ${ }^{82}$ According to the Draft Rules,

President of the Republic of South Africa $v$ Office of the Public Protector (GP) (unreported) case number 91139/2016 of 13 December 2017 para 106.

81 President of the Republic of South Africa $v$ Office of the Public Protector (GP) (unreported) case number 91139/2016 of 13 December 2017 paras 104, 112.

82 Sections 7(1)-(2) of the SIU Act - appointed by the President for the duration of the existence of such a specific Tribunal after consultation with the Chief Justice. Additional members may be appointed by the President from amongst the judiciary including magistrates or the legal profession (ss 7(3)-(5), and assisted by officials of the Justice Department (s 7(7)). 
the PP is both the investigator and the adjudicator of a complaint, which immediately exposes the PP to the charge of procedural unfairness.

Secondly, a Special Tribunal is an open public hearing, ${ }^{83}$ whereas the PP may limit the parties and persons allowed to attend a hearing, thereby exposing the PP to charges of bias and unfairness.

Thirdly, the PP's adjudicative power at the conclusion of a hearing is defined ambiguously as "making a finding on the facts" and "taking remedial action", whereas the adjudicatory powers of a Special Tribunal are clearly set out and its judgments and orders are executed as if they were made by the High Court. ${ }^{84}$ Furthermore, any judgment or order of the Special Tribunal is appealable to the High Court. ${ }^{85}$ By contrast, the PP's Draft Rules are silent on the consequences of the PP's finding. The usual practice has been to take the PP's findings on review but there appears to be no bar either in the Draft Rules or the PP Act to prevent the findings from being taken on appeal.

\section{The decision of the Public Protector}

The PP's decision depends on the nature of the matter and the type of resolution adopted. Rule 43 provides that a complaint is concluded when

a) a preliminary investigation determines that no further action is required;

b) a dispute is resolved by conciliation, negotiation or mediation;

c) the PP furnishes advice to a complainant;

d) an investigation determines that the improper conduct complained of was corrected;

e) the complainant withdraws the complaint; and

f) if the complainant fails to cooperate with the PP in the conduct of the investigation.

As regards the conclusion of an investigation, the rules envisage two distinct procedural stages. The first stage is the publication of the PP's findings and

83 Section 10 of the SIU Act, but S 10(2) allows for a closed-door hearing where necessary.

84 Section 8(2) read with $\mathrm{s} 9(7)$ of the SIU Act.

85 Section 8(7) of the SIU Act - as an appeal against a decision of a single judge of the High Court. 
remedial actions. The second stage is the monitoring of the PP's remedial action. The PP Act provides that the PP must make the findings of an investigation "available to the complainant and any person implicated thereby". ${ }^{86}$ In practice the PP's findings and remedial actions are published in a report which sets out the PP's investigative methodology, the evidence gathered and the reasons for the findings and remedial action.

The rules distinguish between a provisional and a final report. ${ }^{87} \mathrm{~A}$ provisional report is made available to the complainant and any person implicated in the investigation. The implicated person is afforded the opportunity to respond to the PP's provisional findings and proposed remedial action. ${ }^{88}$ The PP determines the manner in which and the date by which the response must be made. ${ }^{89}$ The PP issues a final report after considering the implicated person's response ${ }^{90}$ In practice, the PP provides a copy of the final report to the parties and any implicated person.

The rules provide that when a State organ must take remedial action, the PP may request that State organ to furnish the PP with a written plan stating the remedial action required and the time periods within which the remedial action will be implemented. Thereafter, the PP must monitor the State organ's progress in carrying out the remedial action. ${ }^{91}$

\section{Conclusion}

The Draft Rules clearly need material amendment in many respects, and some of the principal changes required may be briefly noted here. First, the poor grammar and poor choice of words which typify many of the rules must be replaced by the correct legal terminology, which accurately and clearly describes the more technical procedures of the PP's investigation and hearing processes. Especially important are the correct use of the terms that indicate the distinction between discretionary and peremptory actions. For example, the word "discretion" instead of "own initiative" or "own accord". Similarly, the word "may" (meant to be discretionary) and the words

86 Section 8(3) of the PP Act. The PP has discretion as to whether to make its findings available. However, once the PP decides to release those findings the PP must do so "as soon as possible" (s 8(3)). Generally, reports issued by the PP are open to the public unless the PP is of the opinion that there are exceptional circumstances, such as national security, for withhold the report (s $8(2 A))$.

$87 \quad$ Rule 46 and $r 47$.

88 Rule 46(1) and $r$ 46(2).

89 Rule 46(2).

$90 \quad$ Rule 47(1) and $r$ 47(3)(b) and (c).

91 Rule 48(1) and r 48(2). 
"shall" and "must" (meant to be peremptory) should be properly employed. ${ }^{92}$ Also important is a proper explanation of the differences between "receiving information" and "receiving evidence", or the difference between a "complaint" and a "matter"; a "step" and a "procedure". Specific procedures are not properly explained; for example, allowing the PP to reach an "appropriate conclusion" - without explaining the word "appropriate"; and the PP may "exact accountability" - without explaining the word "accountability".

Secondly, it is unclear from an analysis of the Draft Rules whether a chapter 6 hearing is simply a discretionary part of the PP's investigation process or is to be construed as a separate quasi-judicial decision-making forum. The Draft Rules and the PP Act will need amendment to clearly define the procedural role and status of a hearing. In addition, the Draft Rules and the PP Act should also include clear procedural guidelines determining when and how the PP may request the establishment of an inquiry before an independent adjudicator appointed by the President. This would require the Draft Rules to make clear the powers and the procedural differences between an investigation, a hearing and an independent inquiry.

Thirdly, rule 26(1), which states that the rules of evidence shall not apply to a chapter 6 hearing, should be deleted. Although it is recognised that a hearing is primarily meant to be an informal inquisitorial process, some of the more important rules of evidence such as relevance, the rules of documentary evidence, the statutory rule of hearsay and the attorney-client privilege should be obligatory and not at the discretion of the PP, especially with regard to hearings based on serious complaints in the public interest. Less serious complaints and disputes may be diverted to and adjudicated in the chapter 9 ADR processes.

Fourthly, a hearing should incorporate procedural protections such as the privilege against self-incrimination for a witness subpoenaed to testify and the constitutionally entrenched right to silence for those parties implicated by the evidence identified during an investigation or a hearing. Perhaps the prohibition against the admissibility of previous convictions should also apply at a hearing. Similarly, rule 23 , which permits only a limited number of persons to attend a hearing, should be deleted because it unjustifiably

92 Falk v National Director of Public Prosecutions 20121 SACR 265 (CC) para 83 the word "shall" in a statutory provision could be interpreted to mean "must" but also "may". The choice is determined by the meaning which best suits a particular provision within the context of that statute. 
infringes section 34 of the Constitution and the right to be heard in a fair public forum.

Fifthly, the rules of examination-in-chief and cross-examination should apply to the oral testimony of parties and witnesses before a hearing. There is no procedural reason why these adversarial rules cannot exist alongside the direct inquisitorial questioning by the PP.

Sixthly, rule 26(2) should be replaced by a rule which incorporates the standard of prima facie evidence when determining whether a sufficiency of evidence has been reached in which a finding may be made. Rule 27 should be replaced by a rule which states that when evaluating the admitted evidence the PP will make a finding based on the standard of "on a balance of probabilities", and where such a standard has been met order the appropriate remedial action.

Finally, one of the primary problems with the rules is the very broad procedural powers awarded to the PP. The Draft Rules as well as the Act are peppered with terms such as "on the initiative of the PP", "on the PP's own accord", "as the PP deems fit" and "at the direction or request of the PP". This kind of loose language and the very wide discretion awarded to the PP in most of the rules may result in an incompetent or unethical PP manipulating investigatory and hearing procedures to the prejudice of both a complainant and an implicated party. This temptation is reinforced by the wide powers awarded to the PP to frame the issues in dispute, condone any failure to comply with the rules (rule 54), the wide discretion to make any new rules (section $7(11)$ of the $P P A c t$ ), the wide discretion to refuse a party legal representation at a hearing (rule 20(3)(f) and (4)) as well as section 6(8) of the PP Act, which provides that the PP cannot be compelled to appear and answer questions before any court of law relating to any information obtained during an investigation. It also renders the PP vulnerable to charges of bias and procedural unfairness.

The amendments to the Draft Rules should perhaps be modelled on the procedural methodology applied in the SIU Act. As a final comment it may also be necessary to divide the decision-making powers of the office of the PP between the PP and an independent and temporarily appointed adjudicator. The PP should remain in control of the overarching investigatory process, as is required by section 182(1)(a) of the Constitution, but a hearing and/or an inquiry should be constituted before an independent adjudicator in order to shield the PP from the charge of being both investigator and adjudicator in the same cause. 


\section{Bibliography}

\section{Literature}

Oxford Dictionary of English

Oxford Dictionary of English $3^{\text {rd }}$ ed (Oxford University Press New York 2010)

Venter 2017 TSAR

Venter R "The Executive, the Public Protector and the Legislature: The Lion, the Witch and the Wardrobe" 2017 TSAR 176-189

Wolf 2017 PELJ

Wolf $L$ "The Remedial Action of the 'State Capture Report' in Perspective" 2017 PELJ 1-46

\section{Case law}

Democratic Alliance $v$ President of the Republic of South Africa 20131 SA 248 (CC)

Democratic Alliance v South African Broadcasting Corporation Limited 2015 1 SA 551 (WCC)

Economic Freedom Fighters v Speaker, National Assembly 20163 SA 580 (CC)

Falk v National Director of Public Prosecutions 20121 SACR 265 (CC)

President of the Republic of South Africa $v$ Office of the Public Protector (GP) (unreported) case number 91139/2016 of 13 December 2017

Public Protector v Mail \& Guardian 20114 SA 420 (SCA)

South African Broadcasting Corporation v Democratic Alliance 20162 SA 522 (SCA)

South African Reserve Bank v Public Protector 20176 SA 198 (GP)

\section{Legislation}

Constitution of the Republic of South Africa, 1996

Executive Members' Ethics Act 82 of 1998

Housing Protection Measures Act 95 of 1998 
Lotteries Act 57 of 1997

National Environmental Management Act 107 of 1998

Prevention and Combating of Corrupt Activities Act 12 of 2004

Promotion of Access to Information Act 1 of 2000

Promotion of Equality and Prevention of Unfair Discrimination Act 4 of 2000

Protected Disclosure Act 26 of 2000

Protection of Personal Information Act 4 of 2013

Public Finance Management Act 1 of 1999

Public Protector Act 23 of 1994

Public Services Act 103 of 1994

Special Investigating Units and Special Tribunals Act 74 of 1996

\section{Government publications}

Gen N 1085 in GG 33807 of 29 November 2010 (Draft Rules Relating to Investigations by the Public Protector and Incidental Matters)

\section{List of Abbreviations}

$\begin{array}{ll}\text { PELJ } & \text { Potchefstroom Electronic Law Journal } \\ \text { PP } & \text { Public Protector } \\ \text { PP Act } & \text { Public Protector Act } 24 \text { of } 1994 \\ \text { SIU Act } & \text { Special Investigating Units and Special } \\ & \text { Tribunals Act } 74 \text { of } 1996 \\ \text { TSAR } & \text { Tydskrif vir die Suid-Afrikaanse Reg }\end{array}$

